\title{
Changing landscapes for plastic surgery: the effect of the Major Trauma Network on emergency operative workload
}

\author{
Susan A Hendrickson, Denise Osei-Kuffour*, Kazi Rahman, Jonathan Simmons, Shehan Hettiaratchy \\ From London Trauma Conference 2014 \\ London, UK. 9-12 December 2014
}

\section{Background}

The advent of major trauma centres (MTCs) in the UK in 2010 has led to a concentration of complex, polytrauma cases in these centres. The role plastic surgeons play in trauma has increased and evolved over time [1], and currently plastic surgeons input into a wide variety of trauma [2]. Our study aimed to analyse the effect of MTC status on plastic surgery activity at our centre.

\section{Method}

All trauma patients admitted to a London MTC in 2013 who underwent an operation were identified using Trauma Audit \& Research Network data. Operative procedure(s) and operating specialty were recorded. This was compared to local historical data from pre-MTC go-live (2008-2010).

\section{Results}

Of the 2606 trauma calls in 2013, 416 patients required surgical intervention. $29.3 \%$ of these patients $(n=122)$ were operated on by plastics (either as sole operating team or part of multi-specialty team). $76.2 \%(\mathrm{n}=93)$ involved lower limb trauma and 30.3\% ( $=37$ ) upper limb trauma. Emergency general extremity referrals increased from an average of 65/year to 484/year in the period 2011 to 2013, whilst plastics operative workload increased from an average of $53 \mathrm{cases} /$ year to $407 /$ year in the same period. This represents a more than sevenfold increase in the plastic surgery operative workload at our centre.

\section{Conclusion}

There has been a dramatic increase in emergency plastic surgery activity following designation of major trauma

\footnotetext{
* Correspondence: denise.osei@gmail.com

Major Trauma Centre, St. Mary's Hospital, Imperial College Healthcare NHS
} Trust, London, UK 